\title{
The Value Of A Simulation-Based Approach For Teaching Both Survey And Capstone Courses In Business
}

Jane LeMaster, (E-mail: jlemaster@panam.edu), University of Texas, Pan American

\begin{abstract}
A concern in business education is the ability of students to integrate knowledge of the functional areas of business into a meaningful, unified whole. This paper examines the use of a business simulation for teaching the entry-level business survey course and describes the use of the same simulation in the graduate level (MBA) capstone course. An analysis of the value of simulation as an appropriate teaching approach is made for both the survey course and the capstone course. The paper presents the literature on learning styles and preferences, a description of the simulation used, how the study was organized, and the results of student learning and attitudes towards a simulationbased learning style for both courses. The results showed an increase in retention rates and grades for the entry-level survey course and anecdotal evidence for improved leadership skills, communication skills, and understanding of the functional areas of business.
\end{abstract}

\section{INTRODUCTION}

$\mathrm{n}$ business education, increasing emphasis is being placed on student learning outcomes assessment. The American Assembly of Collegiate Schools of Business (AACSB) is stressing continuous improvement, rather than meeting a set of more fixed outcomes as was the case in earlier standards. The new standards are process and outcome-based, and are related to the mission statement of a school of business (AACSB, 1994). Under these newer standards, the performance bar for a school is continually raised. For many schools of business, part of the process of continuous improvement involves developing learning environments that are more student-centered by focusing on a more positive learning environment. Chickering and Gamson (1987) articulated seven principles to enhance student learning. One of the principles addresses, "... respect for diverse talents and ways of learning" (p. 2). An AACSB Task Force report (1998) similarly recognized the need to have teaching styles that matched learning style differences. The rationale for the interest in student-centered learning environments and diversity in learning environments is clear -- that students should learn more in these types of educational settings, and their educational experience should be more satisfying. There is evidence that actual learning does improve when students are in their preferred learning settings (Gregore and Butler, 1984; Okebukola, 1986).

\section{LEARNING STYLES AND LEARNING PREFERENCES}

There are typically two ways in which the terms learning styles and learning preferences are used. One common use of the term learning styles is to refer to the preferences that learners have for different styles of teaching delivery. Kolb (1984) defines learning styles as, "... generalized differences in learning orientations based on the degree to which people emphasize the four modes of the learning process as measured by a self report test called the Learning Style Inventory" (p. 67). The dimensions of learning styles are concrete experience, reflective observation, abstract conceptualization, and active experience. Canfield (1994) defines learning style to be "... the affective component of educational experience, which motivates a student to choose, attend to, and perform well in a course or training" (p. 1). Steward and Felicetti (1992) define learning styles to mean, "...those educational conditions under which a student is most likely to learn" (. 15). All of these definitions focus on the way students learn, not what they learn. The authors address styles, ways or settings in which students prefer to gain knowledge, rather than the cognitive learning process, or what was actually learned. 
Other uses of the term learning style or learning preference refer to ways of teaching or cognitive processes of learning. Curry (1991) distinguishes between learning preference, the favoring of one particular mode of teaching over another; and learning style -- a distinctive and habitual manner of acquiring knowledge, skills or attitudes through study or experience. This definition looks at both pedagogical approaches and ways of learning. Other definitions focus more on cognitive processes. Garger and Guild (1994) look at learning styles as encompassing individual differences in how information is taken in and processed. Lamont and Friedman (1997) refer to the way students learn as learning patterns. Witkin, Moore, Goodenough and Cox (1997) refer to learning styles as differences in how individuals perceive, think and solve problems and learn. The use of the term learning styles depends, then, on whether the emphasis is on the preferences learners have for different ways of learning or different pedagogies; or whether the emphasis is on the actual process by which learning takes place. This paper focuses on preferred educational experiences of students -- or preferred pedagogies.

A number of studies have looked at the preferred learning styles, or pedagogies, of business students in particular. Matthews (1994) found that business students preferred conceptual and social/conceptual-based pedagogies, and had preference for learning with other students rather than learning alone. Nutly and Barrett (1996) concluded that business students prefer pedagogies that are active and concrete. Other studies have examined the use of specific pedagogical approaches, such as team projects (Williams, Beard and Rymer, 1991; Batra, Walvoord, and Krishnan, 1997); experiential learning (Wynd, 1989); gaming and simulation (Laughlin and Hite, 1993; Wellington and Faria, 1996), and Web-based courses (Canzer, 1997).

This paper examines the use of an international business simulation as the primary format for teaching the Introduction to Business survey course and the master's level Strategic Management capstone course in a medium-sized regional university. Simulations have a long history in business education and are most commonly used in upper division and MBA classes, but are not commonly used in lower division classes. The entry-level business class focuses on building the vocabulary of business and presenting a general overview of the various functional areas of business. No specific attempt is made to develop an understanding of the interrelatedness of all the areas. Although simulation has been found to be a good way to integrate ideas, there has been only limited evidence that the use of simulation in business classes actually contributes to increased knowledge or skills. Research shows students respond positively to simulation (Curry and Moutinho, 1992; DeNeve and Heppner, 1997; DeYoung, 1993; Fels, 1993; Keys and Wells, 1992; Keys and Wolfe, 1990; Petranek, 1994; Tompson and Tompson, 1995; Williams and Walker, 1993), but much of the evidence is anecdotal. Recognizing that management games and simulations, "...increase interest, involvement, and enthusiasm...[and] provide rapid, concrete, and consistent feedback..." (Keys and Wolfe, 1990, p. 323), this paper examines simulation as a learning style and presents the results of using an international business simulation in multiple sections of an entry-level business survey course and also presents anecdotal evidence taken from end-of-semester student evaluations in multiple graduate level capstone courses.

The usual pedagogy for undergraduate courses is a textbook, lecture, and then testing over the textbook and lecture material. Typical undergraduate programs in business start with classes in the functional areas of business and progress to a capstone course designed to incorporate knowledge of the subject matter gained from all the previous courses. Waiting until the senior year in college to integrate knowledge may prevent students from gaining a better understanding of their particular functional areas as they take the individual courses in their major areas of study. For those students continuing their formal education in graduate programs in business, a solid understanding of the interdependencies of the functional areas of business are assumed and these students are then asked to apply their knowledge analyzing, evaluating, and synthesizing the relationships in a capstone course. The most common teaching method used for integrating knowledge is through case analysis, and the most common cases are written cases that are most often a part of the required textbook. Using a computer-based business simulation that provides opportunity for submitting and evaluating decision variables allows the students to gain knowledge in the functional areas; allows them to integrate the knowledge; provides the setting to learn how to work effectively in teams; and creates the opportunity to apply the knowledge through presentations and decision-making.

Entering freshmen are typically 17 to 18 years old and in most cases are more comfortable, whether playing Game Boy or sending email, with a mouse and the computer screen than with a pencil and writing pad. For this reason, 
using computer simulation for teaching an introductory business course utilizes, reinforces and enhances the alreadydeveloped learning styles of the average entry-level student. Graduate students may have spent several years in the workforce before returning to school and most will have developed proficient computer skills. This facility should make the use of computer simulation as a teaching tool a comfortable learning environment for the more experienced student as well.

\section{THE SIMULATION MODEL}

The simulation used for this study was designed and administered by Association GlobalView (AGV). The International Business Simulation has been effectively used at the senior and MBA level for many years, and has only recently been adapted to be used with entry-level business students. There are two versions of the simulation, the advanced version and the Introduction version. The primary difference between the two versions is that in the advanced version the students are manufacturers of the product and in the Introduction version the students are primarily only marketers of the product. The simulation is conducted via the World Wide Web supported with WebCT.

Most computer-based simulations are closed systems in that they are used only for a particular class at a particular school, not allowing for interaction with students at other schools. A major difference in the AGV simulation used for this study is that it is an interactive computer-based simulation accessible worldwide through AGV. All schools participating in the simulation interact with each other. Student teams make decisions regarding marketing, production, materials, product, price, employees, and so forth. Students' decisions made in one class at one university are affected by the decisions made by students in other classes at other universities. One can think of it as a worldwide business class with the participants being students at universities around the world. AGV administers the program and the professors at each participating university are the facilitators of the program. Participants in the simulation over the past semesters have been from China, Germany, England, France, Mexico, the Philippines, and the United States.

The simulation includes an on-line "handbook of operating procedures", discussion boards, and a chat room where students can communicate with one another in real time. The operating manual also contains a brief discussion of the various functional area concepts that would be found in a "standard" text, links to web related resource materials to reinforce the concepts, and an on-line real person tutorial help line. The data for this paper is drawn from two semesters of Introduction to Business and graduate Strategic Management classes using the simulation and its resource materials. For the Introduction to Business classes there were 12 sections, 6 using traditional pedagogy, and 6 using simulation only. Comparisons are made of the entry-level classes on grades and retention between the two groups - those using simulation only and those using traditional lecture/textbook pedagogy. For the graduate level Strategic Management classes, evaluation was made using end-of-semester student evaluations that were reviewed for comments specifically regarding the use of the simulation. Student evaluations were selected for acquiring information regarding the effectiveness of the simulation teaching approach because these evaluations are required by the University and are used as an indicator of effectiveness of the instructor. The students view the evaluations as an opportunity to evaluate the specific class. The students also know that the evaluations are anonymous and that the professor will not receive the evaluations until weeks after the semester has ended. Consequently, if the students wish to make derogatory comments they can do so without risk.

Active involvement in the simulation motivates students to use the manual, the Web resources, the tutorial help, and the instructor on a need-to-know basis to seek information. . If instructors are able to facilitate learning by using the students' learning preference and the use of an integrated approach like the simulation, then the students should have a greater understanding of the relationship of their respective specialty areas of study to other areas of business.

\section{THE PARTICIPANTS}

Over the semesters of study for this paper there were a total of 949 undergraduate students in the Introduction to Business classes. The students taking the Introduction to Business course are primarily freshmen and sophomores. Occasionally seniors take the class to fill a last minute elective requirement for their degree. A total of 104 graduate students in the Strategic Management classes participated in the study. At this point in the degree program, the graduate 
students are taking the last 2 or 3 courses in their MBA degree. Although the students are advised to take the capstone course in their final semester, scheduling conflicts may require them to take the class earlier. The prerequisite requirement for taking the capstone course is that the student has completed at least 15 hours (of a 30 hour program) in the degree and these 15 hours should be accounting, economics, finance, marketing, and production operations management.

\section{CLASSROOM ADMINISTRATION OF SIMULATION}

From the first day of class, the concept of starting and operating a business, albeit a simulated business, is applied to how the class is organized. One of the biggest surprises for the students is that there is no standard textbook. There is an electronic text/manual for the course, which gives specific directions on how to make decisions, along with limited examples, and the text includes limited information on the functional areas of business. The instructor must be sure the students are receiving the necessary information regarding the general principles and theories of business so they are able to understand the consequences of their decisions, analyze the outcomes, and evaluate their decisions. Although there is less need at the graduate level these students still require assurances from the instructor regarding their decision processes.

Each simulated company is operated by teams of 3 to 6 members. The entry-level classes meet either two days or three days a week and the graduate classes meet one day a week. For those entry-level classes using only the simulation, meeting days are divided between time spent in the laboratory and time spent in the classroom. Days in the laboratory are for team meetings, decision-making, program entries, informal lectures and team meetings with instructor. Days in the classroom are spent in formal lectures on key concepts only briefly described in the manual. Graduate level meeting days are used primarily for clarification of business concepts and the strategic planning process, team meetings with instructor, and to discuss the general operating environment of the industry with regard to the previous weeks' decision outcomes.

\section{Results}

Two sets of results are presented for this study. The first set of results is from a comparison of grades and retention between using traditional textbook/lecture method and simulation only method for the entry-level Introduction to Business classes. The second set of results is from end-of-semester student evaluations by students in the graduate level Strategic Management course. For the entry-level classes, the same instructors taught both the simulation classes and the classes using traditional pedagogy. Each instructor taught two classes, a simulation-based class and a traditional textbook/lecture based class. This allowed us to control for instructor teaching style between the two groups. The individual instructor decided which of their two classes would be taught using simulation. The same instructor taught all the graduate level strategic management classes used in this study eliminating instructor bias.

\section{Entry-Level Survey Class Results}

The results from the entry-level data revealed that for the simulation-based classes, there were increased retention rates and grade distributions that were skewed to the left (higher grades). A total of 640 students were enrolled in the traditional textbook/lecture method classes over the study period, $66(10.3 \%)$ dropped the class. A total of 309 students were initially enrolled in the simulation only classes of which $20(6.4 \%)$ dropped. Grades improved in a like manner. Of the 640 students originally enrolled in the traditional/lecture format classes, 123 (19\%) students failed (received a grade of F). Of the 309 students enrolled in the simulation only classes, 17 (6\%) failed (see Table 1).

Table 1 Comparative Results for Survey Course

\begin{tabular}{|c|c|c|}
\hline & $\begin{array}{c}\text { Traditional lecture/textbook teaching } \\
\text { approach }\end{array}$ & Simulation only teaching approach \\
\hline Number of students enrolled & 640 & 309 \\
\hline Number of students who dropped course & $66(10.3 \%)$ & $20(6.4 \%)$ \\
\hline Number of students making grade of "F" & $123(19 \%)$ & $17(6 \%)$ \\
\hline
\end{tabular}


An additional finding for each of the semesters the simulation was used was that the percentage of " $\mathrm{A}$ " grades increased while the percentage of all other grades decreased. Instead of grades being skewed to the right as they typically were in the traditional/lecture classes with few to no "A" grades, they were skewed to the left in the simulation classes. The positive change in grade distributions might be related to the students' learned ability to better communicate, to apply knowledge, and the attention to the use of critical thought processes. The question is whether the students' positive grade distributions were due to gains in knowledge or to a "Hawthorne-type effect". Perhaps the grades were better because the students felt they were "special" since only they were participating in the simulation while other classes were using traditional pedagogy.

A comparison was also made to examine any measurable differences in knowledge gained between the two groups, traditional versus simulation. The data for comparison was a comprehensive multiple-choice exam given to all classes comprising the total of the two groups; traditional/lecture method group (six sections) and the simulation only group (six sections). The exam had some bias as it was created from the test-bank supplied with the textbook used for the traditional/lecture method classes. Although this book was not required for the simulation only classes, the title of the book and its availability in the bookstore was presented to the simulation only classes as an option. It is not known if any of the students actually purchased and used the book. One could expect that the simulation group, having had their course taught using the simulation, would perform less well in a traditionally structured testing environment.

The examination results showed no significant differences in grades across all sections when comparing the two groups as a whole or between the groups of each of the instructors. Simulation students, though using a different learning style, performed equally as well on the exam as students taught under traditional pedagogy. In addition, fewer of the students in the simulation only groups dropped the course. These students also gained team building and communication skills that are an inherent requirement with the use of the simulation.

The simulation was challenging, it was fun, and it was different from other classes. This alone may be reason for increased motivation for students not to drop the class and for handling all the extra learning experiences while still mastering the subject matter found in the standard text without studying from the text. Perhaps the greater the interest in the class, the greater the preparation for exams, and the more comfortable the students were with the tools (computer, Web browsing and so forth) the greater the increase in grades. A confounding variable is the inability to completely control for instructor differences. Even when the same professor is teaching multiple sections, the very mix of the class, the time of day (day versus evening classes), and classroom may affect an instructor's presentation style.

\section{Graduate Level Strategic Management Class Results}

Data regarding the effectiveness of learning through the simulation in the graduate level Strategic Management class was collected through end-of-semester student evaluations. The student evaluations are a University requirement for all classes in each fall and spring semester. Faculty merit regarding teaching is partially established by the students' ratings of the instructor on a single question "rating as an instructor". The students may rate the instructor excellent, good, average, fair, or poor. Typically the students rate the instructor based on how they evaluated the particular course. Other questions on which the students may write comments concern what the students liked best and least about the class, what the students thought about the instructional methods used in the class, what changes would enable them to gain more from the class, if they were motivated to work hard, and so forth. It is from these comments that an evaluation of the use of simulation at the graduate level Strategic Management class was made.

Comments ranged from "I feel like I could own my own business now" to "Didn't like it, didn't learn anything. Teacher should teach instead of making the students do all the work." There were 104 participants in the 4 graduate classes studied. Not all students made written comments. Of those making comments, more than $90 \%$ of the comments were positive. The students appreciated the opportunity to have a hands-on experience at running a business. The most frequent dislike was the amount of time required to work on the simulation. The students quickly found the more time they spent talking and working on the decision sets each week, the better understanding they gained, which made it more fun and made them want to spend more time. Consequently, some said they spent a disproportionate amount of time on this class than on any of their other classes. 
Other frequent comments were that the students finally understood what they had learned in the various functional classes they had taken. One student said, "I learned more about accounting in this class than I learned in my accounting class." Another noted they had "finally" learned how "everything fits together". Others commented on how much more proficient they had become with using computer programs like spreadsheets, web pages, and chat rooms.

Like in the graduate level classes, anecdotal evidence of the effects of using the simulation was also noted in the entry-level classes. The instructors observed the process of team building, an increased level of confidence among the team members, and confidence in the use of electronic media. An important argument for using simulation at the entrylevel may be the synoptic view the students gain regarding their education, and the need to understand the various functional areas of business. The simulation draws out the leadership tendencies of students. It teaches communication skills because it requires each student to articulate his or her thoughts to other team members, as well as to the class, in a meaningful way; and to be able to justify and/or defend their decisions. At the very least, using simulation at the entrylevel may increase the level of academic maturity of the student better preparing them for the rest of their academic program.

\section{Teaching Caveats}

Most students have no problem in using the computer to input decisions. They are, however, often frustrated early in the semester because of the different learning styles used in the class. That is, rather than having an instructor standing in front of the class lecturing the days' material, the students are having to ask for information based on what they think they need to know. This is a result of the underlying principle of collaborative learning -- the requirement for students to be partners in the learning process, as opposed to the traditional learning style where the instructor is an authority figure who simply supplies information. Also, the synoptic nature of the simulation manual and the student's need to know information that may be in Chapter 1 or Chapter 15, on page 10 or page 100 is a difficult adjustment for many. Suddenly the textbook is no longer a lock-step book intended to be read sequentially from Chapter 1 through Chapter 22. Now it is a manual of operating procedures with information designed to be used at any time during the course. Students become apprehensive because there is no clearly specified order in which knowledge acquisition is to take place. Students must also cope with the various degrees of risk taking and risk averting among the individual team members.

The entry-level teams are not self-selected, but rather are formed based on interest in a business major, with as much diversity within groups as possible. The graduate level teams are self-selected, primarily because by this time in their degree program they have already worked together in teams, each know the others personalities, and have already determined who works well with whom. Therefore, for the entry-level students, there is substantial within-group adjusting that must take place before the group is able to function as a team. It is not until the very end of the semester, when the students are required to develop a "report to the stockholders" and present their companies' performance that most of the teams are finally able to understand the consequences of their decisions. For the entry-level students, it is at this point, that the group is functioning as a team and has achieved the "performing" stage of group dynamics. The graduate level students tend to reach the "performing" stage much sooner than the entry-level students.

An inherent problem for instructors to any classroom activity that goes outside the traditional textbook and lecture model is the failure of colleagues to consider these deviations as legitimate educational activities (Petranek, 1994). "Critics of [simulation] view fun and learning as incompatible" (Petranek, 1994, p. 516). Additionally, not all students want to participate in a simulation. Petranek (1994) developed 17 principles that describe the maturation process of using simulation. The first principle is that "it takes a great deal of courage to initiate a new teaching style such as simulation" (p. 514). The $12^{\text {th }}$ principle is that, "Simulations are more work than are traditional methods, but simulations are worth it" (p. 520).

\section{CONCLUSIONS}

The strengths of the simulation method of classroom instruction are many. Not the least of these is the increased level of confidence each student acquired at both the entry-level and the graduate level, as a result of being able to make 
decisions and evaluate the consequences of those decisions. Higher retention and better average grades were observed in the entry-level classes using the simulation. At the very least, simulation creates a skills building environment for developing leadership characteristics, team building skills, technology skills, and communication skills, some of the very skills industry has claimed are deficient in today's graduates.

What we know is that the use of this integrated, web-based, international business simulation adds additional support to Nutly and Barrett's (1996) thesis that business students prefer pedagogies that are active and concrete. It also has strong support as an integrative learning tool based on strong positive comments by the participating graduate students. There is still the question, however, of whether the improved performance in the entry-level survey classes was due to the instructor, the simulation program, the individual student, the test environment or was simply a powerful learning environment established through a combination of these factors. The evidence is compelling but not conclusive.

\section{References}

1. AACSB Task Force on Effective and Inclusive Learning Environments (1998). Effective and Inclusive Learning Environments. The International Association for Management Education.

2. American Assembly of Collegiate Schools of Business (1994). Standards for Business Accreditation (revised), AACSB: St. Louis, MO.

3. Batra, M. M., Walvoord, B. E., and Krishnan, K. S. (1997). "Effective pedagogy for student-team projects". Journal of Marketing Education, 19, 26-42.

4. Canfield, A. (1994). Learning Styles Inventory Manual. Los Angeles, CA: Western Psychological Services.

5. Canzer, B. (1997). "Marketing education on the internet: A world wide web based introductory marketing course design for the virtual-u project in distance education at Simon Fraser University”. Journal of Marketing Education, 19, 56-65.

6. Chickering, A.W. and Gamson, S.F. (1987). "Seven principles for good practice in undergraduate education". The Wingspread Journal, special Insert, 9, 1-16.

7. Claxton, C. \& Murrell, P. (1987). "Learning styles: Implications for improving educational practices". ASHEERIC Higher Education Report No. 4. Washington, D.C.: Association for the Study of Higher Education.

8. Curry, B. \& Moutinho, L. (1992). "Using computer simulations in management education". Management Education and Development, 23, 155-167.

9. Curry, L. (1991). "Patterns of learning style across selected medical specialties". Educational Psychology, 11, 247-277.

10. Davis, R. \& Schlais, D. "Distance learning through multiple site information exchange". Unpublished Manuscript.

11. DeNeve, K. M. \& Heppner, M. J. (1997). "Role play simulations: The assessment of an active learning technique and comparisons with traditional lectures". Innovative Higher Education, 21, 231-246.

12. DeYoung, R. (1993). "Market experiments: The laboratory versus the classroom". Journal of Economic Education, 24, 335-351.

13. Fels, R. (1993). "This is what I do, and I like it". Journal of Economic Education. 24, 365-370.

14. Garger, S. and Guild,P. (1984). "Learning Styles: The crucial differences". Curriculum Review, $23,9-12$.

15. Gregore, A.F. \& Butler, K.A. (1984). "Learning is a matter of style". Vocational Education. 53, $27-29$.

16. Keys, B. \& Wells, R. (1992). "A global management development laboratory for a global world”. Journal of Management Development, 11, 4-11.

17. Keys, B. \& Wolfe, J. (1990). "The role of management games and simulations in education and research". Journal of Management, 16, 307-336.

18. Kolb, D.A. (1984). Experiential Learning. Englewood Cliffs, New Jersey: Prentice-Hall, Inc.

19. Lamont, L.M., and Friedman,K. (1997). "Meeting the challenges to undergraduate marketing education". Journal of Marketing Education, 19, 17-30.

20. Laughlin, J.L., and Hite, R.E. (1993). "Game and simulation effectiveness in marketing education: An experimental investigation." Journal of Marketing Education, 15, 39-46.

21. Matthews, D. B. (1994). "An investigation of students' learning styles in various disciplines in colleges and universities". Journal of Humanistic Education and Development, 33, 65-74. 
22. Nulty, D. D. and Barrett, M.A. (1996). “Transitions in students learning styles”. Studies in Higher Education, 21, 333-345.

23. Okebukola, P.A. (1986). "The influence of preferred learning styles on cooperative learning in science". Science Education, 70, 509-517.

24. Petranek, C. (1994). "Maturation in experiential learning: Principles of simulation and gaming". Simulation and Gaming. 25, 513-523.

25. Sims, R. \& Sims, S. (1995). "The Importance of Learning Styles". Understanding the Implications for Learning, Course Design, and Education. Greenwood Press: Westport, CN.

26. Sims, R, Veres, J. \& Shake, L. (1989). "An exploratory examination of the convergence between the learning styles questionnaire and the learning style inventory ii." Educational and Psychological Measurement. 49, 228233.

27. Steward, K. L. and Felicetti, L.A. (1992). "Learning styles of marketing majors". Educational Research Quarterly, 15, 15-23.

28. Tennyson, R. (1987). "Computer-based enhancements for the improvement of learning". Proceedings, Association for Educational Communications and Technology. Atlanta, GA.

29. Tompson, G. H. \& Tompson, H. B. (1995). "Using computer simulations for group projects in business school education." Journal of Education for Business, 71, 97-101.

30. Wellington, W.J. and Faria, A.J. (1996). "The use of simulation games in marketing classes: Is simulation performance due to luck or skill?" Journal of Marketing Education, 18, 50-61.

31. Williams, A.W. \& Walker, J.M. (1993). "Computerized laboratory exercises for microeconomics education: Three applications motivated by experimental economics". Journal of Economic Education. 24, 291-315.

32. Williams, D.L., Beard, J.D. and Rymer, J. (1991). "Team projects: Achieving their full potential”. Journal of Marketing Education, 13, 45-53.

33. Witkin, H.A., C.A. More, D.R. Goodenough, and Cox, P.W. (1977). "Field-dependent and field-independent cognitive styles and their educational implications". Review of Educational Research, 47, 1-64.

34. Wynd, W.R. (1989). “An Experiential Approach to Marketing Education”. Journal of Marketing Education, $11,64-71$. 